\title{
Filament identification and dominance of Eikelboom Type 0092 in activated sludge from wastewater treatment facilities in Cape Town, South Africa
}

\author{
PJ Welz' ${ }^{1,2 *}$, A Esterhuysen ${ }^{1}$, M Vulindlu' $^{2}$ and C Bezuidenhout ${ }^{1}$ \\ 'Microbiology Subject Group, School of Biological Science, North-West University (Potchefstroom campus), Private bag X6001, \\ Potchefstroom, 2520, South Africa \\ ${ }^{2}$ Department of Biological Sciences, Scientific Services City of Cape Town, PO box 16548, Vlaeberg, 7760, South Africa
}

\section{ABSTRACT}

\begin{abstract}
Routine characterisation of activated sludge and identification of the filamentous population by microscopic and/or other non-culture dependent techniques can assist in diagnosing the aetiology of poor performance of wastewater treatment works (WWTWs). In South Africa, most facilities rely solely on physicochemical indicators, treating reactors as 'blackboxes', with the result that process adjustments are often delayed, to the detriment of the environment. This study was performed in order to gain insight into the filamentous population found in activated sludge in Cape Town WWTWs, to compare these with other global and local literature findings, and to build capacity in this science. Physicochemical and plant performance parameters, in terms of nutrient removal and settling, were obtained from routine operational data and assessed in conjunction with the microscopic analyses of activated sludge samples taken over a 6-month period. Hypotheses on the links between filament types and/or plant configurations and/or operational parameters were formulated using existing literature. In order of prevalence, the five most common dominant filament species in 96 activated sludge samples were: Eikelboom Type 0092, Eikelboom Type 1851, nocardioforms, Microthrix parvicella and Eikelboom Type 021N. In order to compile a statistically significant database, it is recommended that an extensive nationwide study is conducted to link filament types with plant configurations, operational parameters and geographical locations.
\end{abstract}

Keywords: activated sludge, bulking, identification, filament, Type 0092

\section{INTRODUCTION}

The successful treatment of wastewater is reliant on the continued presence of a robust microbial consortium. In activated sludge systems, a variety of bacteria grow in filamentous forms that may or may not form part of the floc structure (Eikelboom, 2000; Jenkins et al., 2004). Some filament types form bridges between flocs or have hydrophobic cell walls that hamper floc settling and cause sludge bulking and/or foaming. Particular process conditions are strongly associated with the proliferation of 'bulking' filament types (Eikelboom, 2000; Jenkins et al, 2004; Lakay et al., 1999).

Most municipalities in South Africa, including the City of Cape Town, treat activated sludge reactors as 'black-boxes' and rely on chemical indicators of system health. Performance problems are thus usually addressed in a reactive and not a proactive manner. Microscopic analysis of activated sludge is a simple, cost-effective procedure that can add value to the arsenal of tests currently performed at laboratories affiliated to WWTWs. At present, expertise in filament identification is only available at the East Rand Water Care company (ERWAT),

\footnotetext{
* To whom all correspondence should be addressed. Current address: Biocatalysis and Technical Biology Research Group, Cape Peninsula University of Technology, PO Box 1906, Bellville, 7535

푱 +2721953 8498;

e-mail:welzp@cput.ac.za

Received 8 April 2014; accepted in revised form 7 October 2014.
}

and the Institute for Water and Wastewater Technology at Durban University of Technology (DUT). At DUT, ongoing research is being conducted using non-microscopic methods of filament identification.

In a global context, there has been considerable progress in the quest towards accurately identifying the filamentous populations in activated sludge by culture-dependent and cultureindependent methodologies (Aruga et al., 2002; Ramothokang, 2003; Yoon et al., 2010). The latter include fluorescent in-situ hybridisation (FISH) with probes targeting the 16S rRNA gene (e.g. Spiers et al., 2009, 2011; Yoon et al., 2010); high throughput pyrosequencing of the $16 \mathrm{~S}$ rRNA gene (e.g. Guo and Zhang, 2012; Marrengane et al., 2011); compilation of clone libraries (e.g. Yoon et al., 2010), and excision and sequencing of bands obtained from denaturing gradient gel electrophoresis (DGGE) (e.g. Gulez et al., 2009). The application of these methods has resulted in the identification of many morphological filament types, originally characterised using microscopy, to phylum and/or genus and/or species levels. FISH is the most simple and suitable of these technologies for routine use, with many probes being commercially available (Martins et al., 2003; Nielsen et al., 2009). An added advantage of FISH is that it can be used to identify non-filamentous species, including nitrifiers, and phosphorus- and glycogen-accumulating organisms (Eschenhagen et al., 2003). However, the specificity of FISH probes may result in exclusion of particular filaments due to mismatches (Liu and Seviour, 2001). In addition, each filament type requires at least one probe, with more than one probe often being needed for a single morphotype, making the method too expensive and time-consuming for routine use in the South African context. 
It is argued that filament identification using microscopy is subjective, and thus prone to error (e.g. Nielsen et al., 2009). In a study comparing conventional microscopy with FISH and DGGE for filament identification, Gulez et al. (2009) reported anomalies with each method and recommended the use of more than one technique for identification. While this is feasible for research purposes, the authors of this manuscript are of the opinion that there is still a place for conventional microscopy if performed correctly by well-trained personnel. It is currently the only method that is rapid and costeffective enough for routine application. Microscopic sludge analyses provides a holistic approach to the characterisation of activated sludge; apart from filament identification, additional sludge characteristics, including the morphology of the flocs, the presence of monocolonies and the abundance and identification of protozoa and metazoa can be determined concurrently.

This study is the third filamentous survey reported in South Africa. Two previous studies were performed on activated sludge from biological nutrient removal (BNR) WWTWs: (i) nationwide (33 WWTWs, locations not given), and (ii) in KwaZulu-Natal (KZN; 6 WWTWs) (Blackbeard 1986, Lacko et al., 1999). This study compares the filamentous population identified in activated sludge from 11 WWTWs in the City of Cape Town with previous studies. A short discussion on selected dominant filaments types, together with some noteworthy findings, is included. The occurrence of filamentous organisms in association with bulking sludge, selected process conditions and WWTW configurations is also reported and discussed.

\section{MATERIALS AND METHODS}

\section{Wastewater treatment works (WWTWs)}

Eleven WWTWs were included in the study. Three plants were designed and operated in a Modified Ludzack-Ettinger (MLE) configuration/mode designed for biological organic carbon and ammonia removal, and were designated MLE1 to MLE3. MLE2 was used to treat domestic effluent and MLE1 and MLE3 were used to treat industrial effluent. MLE1 consisted of 3 reactors, all of which were included in the study. Five WWTWs, designated UCT1 to UCT5, were designed and operated in a University of Cape Town (UCT) configuration/ mode for biological organic carbon and nitrogen removal. UCT1 was used to treat mixed domestic and industrial effluent, while UCT2 to UCT4 were used to treat domestic effluent. Two plants, designated 5SB1 and 5SB2, were designed and operated in a 5-stage Bardenpho configuration/mode for biological organic carbon, nitrogen and phosphorus removal. Both were used to treat mixed industrial and domestic effluent. One carousel plant was operated in a 3-stage Phoredox (3SP1) configuration designed for biological organic carbon, nitrogen and phosphorus removal. This WWTW was located in an environmentally sensitive area and was used to treat domestic effluent.

\section{Sample collection}

Activated sludge samples were taken on a weekly basis by the operational staff at the various WWTWs and sent to Scientific Services at the City of Cape Town for analyses. For this study, samples were analysed on a monthly basis in 2007. Grab samples were taken in plastic bottles from the weir overflow sites exiting the bioreactors. Samples were processed on the day of collection. The 'influent' samples were taken from inflow to the reactors after primary settling and the 'effluent' samples were taken from the secondary clarifiers.

\section{Routine analyses}

Routine analyses performed by staff at Scientific Services, the results of which were used in this study, were: chemical oxygen demand (COD), volatile suspended solids (VSS), mixed liquor suspended solids (MLSS), diluted sludge volume index (DSVI), according to the methods described by Clesceri et al. (2005). The concentrations of total Kjeldahl nitrogen (TKN), ammonia $\left(\mathrm{NH}_{3}\right)$, nitrates/nitrites $\left(\mathrm{NO}_{2} / \mathrm{NO}_{3}{ }^{2-}\right)$, total phosphates (TP) and ortho-phosphates $\left(\mathrm{PO}_{4}^{3-}\right)$ were determined using a Lachat (Lachat instruments, Loveland, USA), flow injection analyser with the respective QuickChem methods 10-107-06-2-D, 10-107-06-1-A, 10-107-06-1-A, 10-107-04-1-A, 10-115-01-1-E, 10-115-01-1-A, according to the manufacturer's instructions.

\section{Microscopic analyses}

The microscopic analysis was performed on samples without prior knowledge of the results of the routine analyses, according to the methods described by Eikelboom (2000) and Jenkins et al. (2004).

Three wet mounts were prepared from each sample and examined at 100, 200 and 400 times magnification, using a phase contrast lens. If increased magnification was required, the mounts were also examined at 1000 times magnification, using an oil immersion lens. The morphological characteristics (size, shape, structure, strength), filament index, abundance of monocolonies, and selected filament characteristics were determined from examination of the wet mounts. The wet mounts were also used to perform quantitative and qualitative analysis of the protozoan and metazoan populations. Not all of these results are presented in this manuscript, but were used to substantiate hypotheses for nutrient removal performances (Eikelboom, 2000; Jenkins et al., 2004).

Two slides were prepared for staining from each of the undiluted mixed liquor samples. The first slide was stained by the Gram method described in the manual of the Standard Operating Procedures of the Health Protection Agency (HPA) of the United Kingdom. 0.5\% crystal violet was used as the initial stain, acetone as the decolourising agent, and dilute carbol fuschin as the counterstain. The second slide was stained by the Neisser method described by Eikelboom (2000). The stained slides were examined at $1000 x$ magnification using an oil immersion lens.

\section{Sulphur storage test}

The sulphur storage test was performed on all mixed liquor samples according to the method described by Eikelboom (2000).

\section{Calculation of food to microorganism (F/M) ratio}

$$
F M=Q \times[C O D] / V \times[M L V S S]
$$

where:

$Q=$ flow rate into bioreactor

$V=$ bioreactor volume 


\section{RESULTS AND DISCUSSION}

In total, 96 samples taken from 5 MLE, 7 UCT and 4 5SB reactors at $11 \mathrm{WWTWs}$ were analysed. Sixteen filament types were identified, with eight being found as both dominant and secondary and eight as secondary only (Fig. 1).

Table 1 gives a comparison of the results of this study with two previous studies in which the filamentous populations in activated sludge were identified: (i) A once-off survey including 33 BNR WWTWs, locations not given (Blackbeard et al., 1986), and (ii) A bi-weekly survey (May to October) from 6 BNR WWTWs in KZN (Lacko et al., 1999).
In terms of overall prevalence, some notable differences between the three studies were found, the most important being the fact that Eikelboom Type 0092 was not identified in any of the six WWTWs from KZN, but was present in almost all samples from the other two studies (44 WWTWs). The Eikelboom Type 0092 morphotype has been widely documented as a dominant filament in activated sludge systems world-wide, including Asia, Europe, North America and Australia (Martins et al., 2003). However, the absence of this organism has been previously documented in other locations besides KZN (for review, see Martins et al., 2003). The WWTW configurations, which played a role in the selective process in

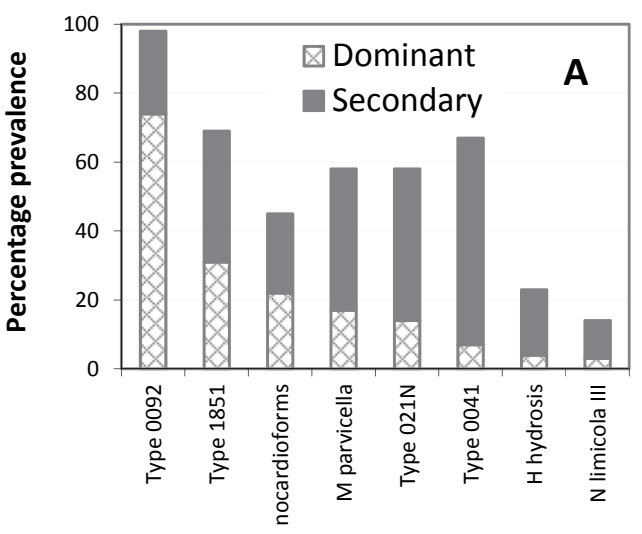

Filament type

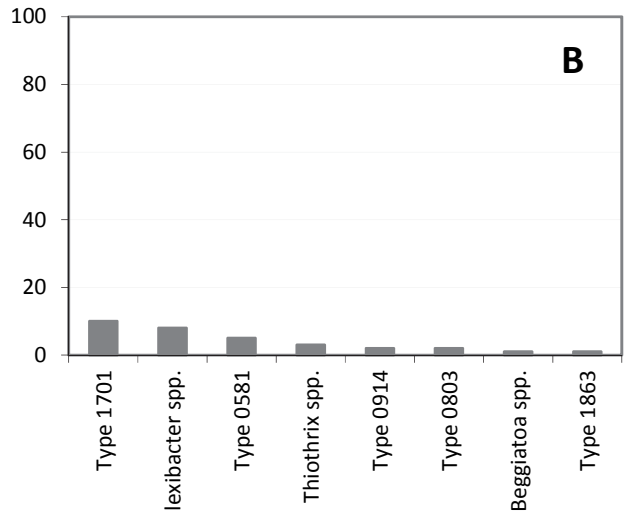

Filament type
Figure 1

Filaments found as dominant and secondary species (A) and secondary species only (B), in order of prevalence from left to right

\begin{tabular}{|c|c|c|c|c|c|}
\hline \multicolumn{6}{|c|}{$\begin{array}{c}\text { TABLE } 1 \\
\text { Overall prevalence and prevalence as dominant filaments in } 3 \text { filamentous surveys in South Africa }\end{array}$} \\
\hline & \multicolumn{3}{|c|}{ Overall filament prevalence (\%) } & \multicolumn{2}{|c|}{ Dominant filament (\%) } \\
\hline & Blackbeard et al. & Lacko et al. & Welz et al. & Blackbeard et al. & Welz et al. \\
\hline Type 0092 & 94 & 0 & 98 & 82 & 74 \\
\hline Type 1851 & 58 & 100 & 69 & 21 & 31 \\
\hline M. parvicella & 76 & 100 & 58 & 33 & 17 \\
\hline Type 0041 & 85 & 67 & 67 & 39 & 7 \\
\hline Type 021N/Thiothrix group I & 0 & 50 & 58 & 0 & 14 \\
\hline Nocardioforms ${ }^{\star}$ & 24 & 67 & 45 & 15 & 22 \\
\hline H. hydrosis & 21 & 33 & 23 & 12 & 4 \\
\hline N. limicola III/II ** & 21 & 83 & 14 & 6 & 3 \\
\hline Type 1701 & 0 & 50 & 10 & 0 & 0 \\
\hline Flexibacter spp. & 0 & 0 & 8 & 0 & 0 \\
\hline Type 0581 & 0 & 0 & 5 & 0 & 0 \\
\hline Thiothrix spp./group II ${ }^{\star * \star}$ & 6 & 50 & 3 & 3 & 0 \\
\hline Type 0914 & 70 & 50 & 2 & 33 & 0 \\
\hline Type 0803 & 27 & 0 & 2 & 17 & 0 \\
\hline Beggiatoa spp. & 0 & 33 & 1 & 0 & 0 \\
\hline Type 1863 & 9 & 0 & 1 & 6 & 0 \\
\hline Type 1702 & 3 & 0 & 0 & 0 & 0 \\
\hline Type $0675^{\star * \star \star}$ & 73 & 67 & Type 0041 & 45 & Type 0041 \\
\hline Type 0961 & 3 & 0 & 0 & 0 & 0 \\
\hline S. natans & 0 & 33 & 0 & 0 & 0 \\
\hline
\end{tabular}

${ }^{*}$ Eikelboom (2000) and Jenkins et al. (2004), respectively use the term Actinomycetes and Nocardia spp. Also previously referred to as Nocardia amorae-like organisms (NALO)

${ }^{* * E i k e l b o o m ~(2000)}$ no longer classifies N. limicola II as a separate entity. Both N. limicola II and N. limicola III are now classed as N. limicola III that includes all strains with similar morphological characteristics. Blackbeard et al. (1986) do not separate N. limicola into types

${ }^{* * *}$ Lacko et al. (1999) separate Thiothrix I (17\% occurrence and dominance) and Thiothrix II (33\% occurrence and dominance) into Thiothrix genus and separate from Eikelboom Type $021 \mathrm{~N}$

****Eikelboom (2000) now classifies Type 0675 as part of Type 0041 


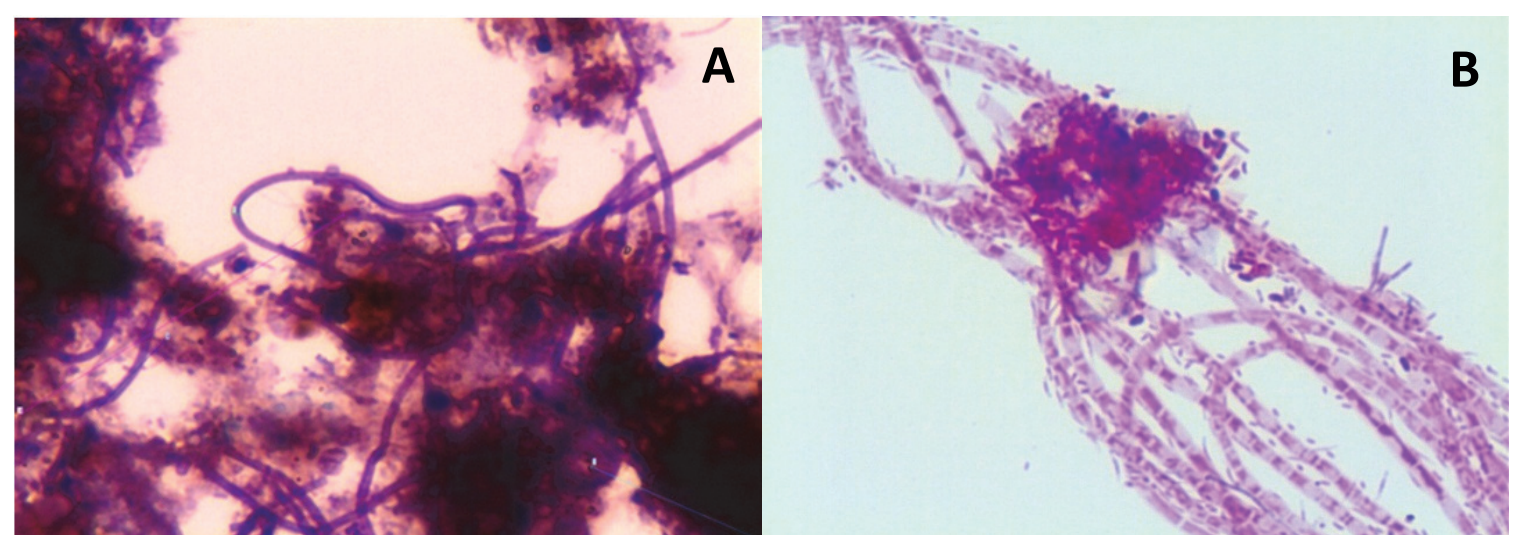

Figure 2

Neisser stain of Eikelboom Type 0092 (Neisser positive, blue), showing how this filament forms the backbone of the floc structure (A), and Gram stain of Eikelboom Type 021N, in activated sludge from UCT1.

Cape Town, may have been a factor to consider. Indeed, Madoni et al. (2000) have shown that Microthrix parvicella (M. parvicella) and Type 0092 are substrate competitors which dominate in WWTWs designed for organic carbon removal, and organic carbon and nitrogen removal, respectively. This is consistent with the findings of this study, and is discussed in more detail later in the manuscript.

\section{Association of dominant species with configuration, process conditions and bulking in Cape Town WWTWs, and comparison with literature findings}

The presence of Eikelboom Type 0092, 1851 and $021 \mathrm{~N}$, as well as $M$. parvicella, Thiothrix spp. and nocardioforms as dominant filaments was particularly notable. By comparing the presence of these filaments with process conditions and other associations described in literature, hypotheses for dominance of these filaments are presented. In addition, the connection of these filaments with bulking phenomena and WWTW configurations is discussed.

\section{Eikelboom Type 0092}

The presence of Type 0092 filaments in activated sludge is desirable as they typically form the backbone of the floc infrastructure (Fig. 2), thereby contributing to floc stability (Spiers et al., 2009; Yoon et al., 2010). Using FISH, Type 0092 has been designated to the phylum Chloroflexi, including members of the Caldilineae class (Spiers et al., 2009; Yoon et al., 2010). M. parvicella is capable of utilising 'higher' fatty acids (e.g. oleic acid) as a carbon source, which can provide it with a competitive advantage in high-fat environments (Eikelboom, 2000; Rossetti et al., 2005). However, the presence of fatty acids is not a requisite for the growth of this organism and it has been shown to proliferate using simple and complex carbohydrate carbon sources (Rossetti et al., 2005). In many treatment plants, there is often a seasonal, temperature-dependent, successional dominance between M. parvicella and Type 0092 and it has been suggested that this is because both of these organisms can utilise the same substrate, making them capable of thriving in similar nutritional environments (Eikelboom, 2000; Martins et al., 2004). Indeed, M. parvicella, Type 0092 and Type 0041/0675 are grouped together (Group IV) as aerobic- anoxic- anaerobic- zone growers which are present in conditions of high solids retention, possibly utilising particulate substrates for growth (Martins et al., 2005). Although BNR WWTWs with low F/M ratios, high solids retention times and predominantly particulate and slowly biodegradable COD (SBCOD) have been associated with the selection of Type 0092 (Eikelboom, 2000; Casey et al., 1999a, 1999b, 1999c; Jenkins et al., 2004; Martins et al., 2003), there is also research which discounts the influence of $\mathrm{F} / \mathrm{M}$ ratio on the selection process (Noutsopoulos et al., 2006).

In this survey, Type 0092 was extremely ubiquitous, being found in 94\% (June and October) and 100\% (July, August, September, November) of samples and being dominant in 56\% to $81 \%$ of samples. In samples that were deemed to be prone to bulking by virtue of elevated DSVI and/or FI, Type 0092 was only found in $63 \%$ and $61 \%$ of the samples, respectively (Table 2). Type 0092 was present as the sole dominant species in UCT3, in which the bulking indicator tests (DSVI and FI) were positive. However, microscopic investigation showed that the bridging between flocs which was responsible for the high FI was due to the presence of a mixed secondary consortium (Table 3). In all other instances, when bulking phenomena were present, co-dominant species were also present (Table 3). These results are consistent with literature expectations that Type 0092 is seldom implicated in bulking (Spiers et al., 2009; Yoon et al., 2010).

Type 0092 dominated the filamentous population in a range of $\mathrm{F} / \mathrm{M}$ ratio environments ( 0.09 to $0.42 \mathrm{kgCOD} / \mathrm{kgVSSday}^{-1}$ ) and reactor configurations (UCT, 5-stage Bardenpho, 3-stage Phoredox; Table 3). However, it did not dominate in any of the samples taken from 3 MLE WWTWs. This is not unexpected,

TABLE 2

Correlation of overall filament prevalence and prevalence when bulking indicators were present

\begin{tabular}{|l|c|c|c|}
\hline & Overall & $\mathrm{FI} \geq 3$ & $\mathrm{DSVI} \geq \mathbf{1 5 0}$ \\
\hline Type 0092 & $98 \%$ & $63 \%$ & $61 \%$ \\
Actinomycetes & $45 \%$ & $33 \%$ & $43 \%$ \\
Type 021N & $58 \%$ & $30 \%$ & $26 \%$ \\
Type 1851 & $69 \%$ & $44 \%$ & $35 \%$ \\
M. parvicella & $58 \%$ & $7 \%$ & $13 \%$ \\
N. limicola III & $14 \%$ & $4 \%$ & $4 \%$ \\
\hline
\end{tabular}


because the organism has been shown to dominate in BNR WWTWs (Madoni et al., 2000; Martins et al., 2003) and the simple MLE configuration is not designed for denitrification.

The results of this study, together with previous literature findings, strongly suggest that the qualitative nature of COD dictated by WWTW configuration and operating mode played a more pivotal role than the quantitative nature of COD (F/M ratio in range 0.09 to $0.42 \mathrm{kgCOD} / \mathrm{kgVSS} d a y^{-1}$ ) in the selection of Type 0092. This is an important factor because, if $M$. parvicella (an undesirable species) and Type 0092 (a desirable filament type) are seen as niche competitors, growth of the former over the latter would be advantageous (Eikelboom, 2000; Martins et al., 2003). It has been suggested that in similar nutritive environments, temperatures $<15^{\circ} \mathrm{C}$ favour the growth of M. parvicella over Type 0092, and during cold periods a reduction in sludge age may discourage the growth of the former (Eikelboom, 2000; Noutsopoulis et al., 2006). In Cape Town, which enjoys a Mediterranean climate, temperature is unlikely to affect filament selection, which is borne out by the fact that Type 0092 dominated during both winter and summer. However, temperature may be a factor to consider in other geographical locations in South Africa.

\section{Eikelboom Type 1851}

Like Eikelboom Type 0092, this filament is associated with low-loaded WWTWs (Eikelboom, 2000). A strain of Type 1851 has been isolated by micromanipulation and identified as belonging to the phylum Chloroflexi and most closely related to the species Roseiflexus castenholzii (Beer et al., 2002). It has been shown that the growth of Type 1851 may be suppressed by the use of a selector, intermittent feeding and the presence of anoxic or anaerobic conditions (Eikelboom, 2000; Jenkins et al., 2004).

Eikelboom Type 1851 was the second most common and dominant filament identified in this study, being found in $69 \%$ of samples (Fig. 1). The filament was the major dominant species in all samples taken from the three MLE WWTWs included in the study, two treating industrial and one treating domestic effluent (Table 3). The MLE configuration was highly selective for Type 1851, irrespective of the nature of the influent. In sludge from MLE1 (treating industrial effluent), and MLE2 (treating domestic effluent), Type $021 \mathrm{~N}$ and nocardiofroms, respectively, were co-dominant. At both these sites, bulking conditions were encountered. In sludge from MLE3, treating industrial effluent, Type 1851 was the sole dominant species, and bulking indicator tests were negative. It has been documented that large numbers of Type 1851 may be present in facilities treating agri-industrial effluent, where an abundance of low molecular weight compounds are expected (Eikelboom, 2000). According to Eikelboom (2000), Type 1851 is commonly found, but almost never dominates in domestic WWTWs, which is contrary to the findings in this study, and other South African studies (Table 1). All of the MLE plants included in the study experienced constant or intermittent problems with nitrification due to overload and/or lack of aeration associated with mechanical failures. Further work is needed to determine whether the selection of Type 1851 in MLE WWTWs in Cape Town would be a feature under optimal operating conditions.

\section{Microthrix parvicella}

M. parvicella is commonly found in domestic BNR WWTWs with low F/M ratios, and is a nuisance organism, causing bulking sludge and scum formation, especially during winter in colder climates (Ekama et al., 1984; Eikelboom et al., 2000; Jenkins et al., 2004). Wastewater with high concentrations of 'higher' fatty acids, e.g., oleic acid, are utilised selectively by M. parvicella and it has been postulated that surface lipases allow $M$. parvicella to take up and store long-chain fatty acids under anoxic as well as anaerobic conditions, providing the filament with a competitive advantage (Nielsen et al., 2002). High concentrations of fatty acids are formed when there are long retention times in sewers, primary settling tanks or anaerobic zones, which provide ideal conditions for the proliferation of M. parvicella (Jenkins et al., 2004). Under laboratory conditions, it has been shown that foaming problems due to M. parvicella at low temperatures can be alleviated by reducing the age of the sludge to change the morphology of the filament (Noutsopoulos et al., 2006), and that that the presence of free ammonia as a source of nitrogen can cause bulking by $M$. parvicella (Tsai et al., 2003). Specific strategies that either have been used (with varying degrees of success) or show promise for the control of filamentous overgrowth of $M$. parvicella include: reducing solids retention times, using pre-flotation to reduce the lipid fraction, increasing the dissolved oxygen concentration (ideally by employing selectors), and adding polyaluminium hydrochloride (Jenkins et al., 2004; Madoni and Davoli, 2002; Nielson et al., 2002; Roels et al., 2002). The latter appears have a selective toxic effect on the proliferation of $M$. parvicella, possibly by altering cell surface characteristics resulting in detrimental morphological changes (Roels et al., 2002; Rossetti et al., 2005).

M. parvicella was the fourth most abundant and dominant filament identified in this study (Table 1), being present in $13 \%, 56 \%, 75 \%, 81 \%, 69 \%$ and $56 \%$ of samples from June to November, respectively. M. parvicella was only present as a secondary species in one of the three WWTWs with MLE configuration, and did not dominate in any. It was present as a secondary species in the two WWTWs with 5SB configuration. However, in all but one WWTW with a UCT configuration, M. parvicella dominated intermittently. In two of these (one in August, one in September), it was present for 1 month only, when on both occasions it co-dominated with Type 0092. In the remaining 2 UCT WWTWs, it dominated for 3 and 5 of the 6 months, respectively, and in both instances, co-dominated for 3 months with Type 0092.

Apart from a low prevalence in June there was no obvious change in the occurrence of this organism from winter to summer in Cape Town (see discussion on Type 0092). A long-term study, over at least 1 year, is needed to fully assess the impact of temperature on the growth of this filament in different geographical locations in South Africa.

The expected bulking problems associated with the growth of this organism were not apparent as M. parvicella was only encountered in $13 \%$ and $7 \%$ of samples with elevated DSVI and FI, respectively (Table 3 ). However, samples were taken by municipal staff that did not document the presence of bulking and/or foaming in situ. Ex-situ indicators (DSVI and FI) were used to determine the presence of bulking. It therefore cannot be categorically discounted that the organism may have been associated with foaming, and possibly bulking, in situ.

\section{Eikelboom Type 021N/Thiothrix}

Historically, genotypic and phenotypic differences have led to the identification of two phylogenetic clusters within the Thiothrix genus, the T. nivea group (also known as Thiothrix I) 
and the Eikelboom Type $021 \mathrm{~N}$ group (also known as Thiothrix II or T. Eikelboomii) (Aruga et al., 2002; Jenkins et al., 1996; Kanagawa et al., 2000; Wagner et al., 1994). To avoid confusion, the two groups have been named using the classical nomenclature of Thiothrix and Eikelboom Type 021N, respectively, in this manuscript. Many researchers have argued that each should be classified as a separate genus. However, after exhaustive analyses, Chernousova et al. (2012) have recently proposed that each group should form an evolutionary branch within the same genus. To reach this conclusion, a range of genotyping and phenotyping methods were used by these authors, including the amplification and sequencing of the $16 \mathrm{~S}$ rRNA and gyrB gene fragments, and analysis of the secondary structure of $16 \mathrm{~S}$ rRNA of species from each group.

Eikelboom Type $021 \mathrm{~N}$, is reported to be strictly aerobic and able to grow over a broad $\mathrm{F} / \mathrm{M}$ range, especially in the presence of easily biodegradable substrates (Eikelboom, 2000). These filaments can also utilise hydrogen sulphide as a source of energy, which, together with the predilection for biodegradable compounds, allows for abundant growth in 'septic' wastewater (Eikelboom, 2000, Jenkins et al., 2004). In this study, Type 021N and bulking indicators were often present simultaneously (Table 2). The filament was a major dominant species in $3 \mathrm{WWTWs}$, all of which were either treating industrial effluent (MLE1) or mixed domestic/industrial effluent (UCT1, 5SB1; Table 3). In the activated sludge from UCT1, and 5SB1, Thiothrix was present simultaneously with Type $021 \mathrm{~N}$ (data not shown). In addition, rosettes, which are associated with the presence of sulphides (Eikelboom, 2000), were noted. UCT1 experienced long-term problems with nitrification which have recently been rectified by increasing the aeration rates well over design parameters (anecdotal evidence, city engineer). Although the concentrations of sulphur compounds were not measured, the results of this study strongly suggest that the sludge became septic due to insufficient aeration at this WWTW. This affords an excellent example of how filament identification can be applied to solve operational problems at WWTWs.

\section{Nocardioforms}

This Gram-positive branching filamentous group of organisms, previously also known as Nocardia amarae-like organisms (NALO), and termed Actinomycetes by Eikelboom (2000), were the most common cause of bulking and foaming in the United States in the 1980s (Richard et al., 1982; Strom and Jenkins, 1984). Like M. parvicella, these filaments can utilise the fat fraction of wastewater for growth and their hydrophobic/lipophilic cell wall causes them to float and form scum (Eikelboom, 2000, Jenkins et al., 2004). Nocardioforms were the sixth-most prevalent, and the third-most dominant filaments in the Cape Town WWTWs (Fig. 1). This indicates that the presence of conditions that were selective for the growth of these filaments offered them a competitive advantage. The presence of nocardioforms was strongly associated with bulking in this study (Table 2, Table 3), which is consistent with literature expectations (Table 2).

\section{Evaluation of selected operational parameters}

A number of operational parameters were evaluated in terms of WWTW operation and filament dominance, and some inferences were made from these results (Table 3). Parameters that were taken into account included weekly measurements of influent and effluent ammonia $\left(\mathrm{NH}_{3}\right)$, nitrates/nitrites
$\left(\mathrm{NO}_{2}{ }^{-} / \mathrm{NO}_{3}{ }^{2-}\right)$, influent and effluent ortho-phosphate $\left(\mathrm{PO}_{4}^{-}\right)$, and influent and effluent $\mathrm{COD}$ concentrations. Concentrations of $\mathrm{NH}_{3}, \mathrm{NO}_{2}{ }^{-} / \mathrm{NO}_{3}{ }^{2-}$, and $\mathrm{PO}_{4}{ }^{-}$in the effluent were classified as 'high', 'moderate' or 'low' if $90 \%$ of these fell within a range of stipulated values (for values, see legend to Table 3 ). Concentrations that spanned the range between low and high were designated 'erratic'. This study was not intended to provide an exhaustive account and statistical analyses of the process parameters, but to gain preliminary insight into how the performance, selected process conditions and WWTW configurations impacted the microbial community succession in the activated sludge. Larger numbers of WWTWs and samples need to be included in order to extract statistically significant correlations.

COD removal was satisfactory $(>82 \%)$ in all WWTWs, barring on two occasions at 5SB2, treating 25/75\% industrial/ domestic effluent (data not shown). In WWTWs where nitrogen and/or phosphorus removal performances were above or below WWTW design expectations, hypotheses for the mechanisms responsible are provided in Table 3. These hypotheses are based on literature reports and extensive data analysis, including nutrient ratios, loading parameters, and empirical observations.

Kujawa and Klapwijk (1996) have shown that in UCT systems a COD ratio of $\mathrm{COD} / \mathrm{TKN}$ of above 8.4 is necessary to supply sufficient electron donors for complete heterotrophic denitrification to take place. Ekama et al. (1984) have shown that a TKN/COD ratio of $>0.14$ results in carry-over of nitrates and nitrites from the anoxic into the anaerobic zone, which has a negative effect on P removal. In addition, Liu et al. (1997) have determined that low $\mathrm{COD} / \mathrm{P}$ ratios $(10-20 \mathrm{mgCOD} / \mathrm{mgP})$ are necessary for phosphorus-accumulating organisms (PAOs) to outcompete glycogen-accumulating organisms (GAOs) for substrate. Studies by Oehman et al. (2007) have suggested that $\mathrm{pH}$ and qualitative and quantitative differences in the short chain volatile fatty acid (VFA) profile has an effect on the metabolism of these competitors.

In this study, there was poor nitrification and excellent phosphorus removal, either constantly or intermittently in MLE1, MLE2, MLE 3 and UCT1. The lack of nitrification translated into low effluent nitrate and nitrite concentrations. The results strongly suggest that the lack of nitrates and nitrites in the anoxic zones of the MLE WWTWs and UCT1 resulted in these zones being turned into de-facto anaerobic zones, thereby enhancing phosphorus removal by PAOs (Table 3). Conversely, low concentrations of ammonia and high concentrations of nitrates/nitrites and phosphates were measured in the effluent from 5SB1, 5SB2 and 3SP, and intermittently in UCT4 and UCT5. It is proposed that a lack of electron donors associated with low COD/TKN ratios retarded denitrification in the UCT reactors, as periods of low denitrification correlated with lower $\mathrm{COD} / \mathrm{TKN}$ ratios and vice versa (Table 3 ).

Ironically, the lowest total- and ortho-phosphate concentrations were measured in the MLE WWTWs and UCT1 (during periods of poor nitrification), while the highest concentrations were measured in the effluent from those WWTWs specifically configured (and operated) for enhanced biological phosphorus removal ((5SB1, 5SB2, 3SB); Table 3). In these, it is suggested that reduced denitrification resulted in the anaerobic zones being turned into de-facto anoxic zones and/or competition for substrate by glycogen and phosphorus-accumulating organisms, and/or that unfavourable VFA profiles or $\mathrm{pH}$ levels hampered phosphorus removal (Table 3). In-depth research, including measurement of nitrates/nitrites, phosphates, COD, 


\begin{tabular}{|c|c|c|c|c|c|c|c|c|c|c|c|c|c|}
\hline 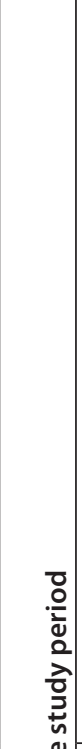 & 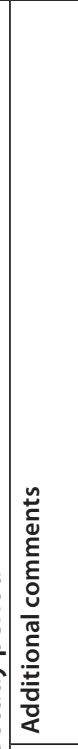 & 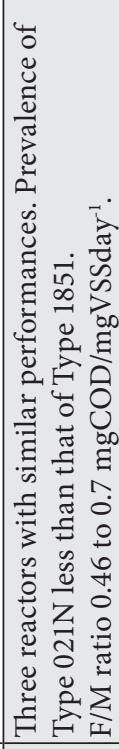 & 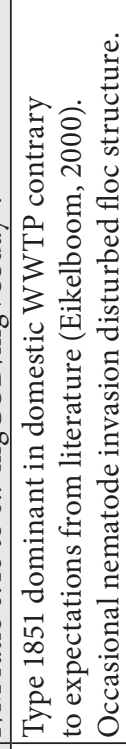 & 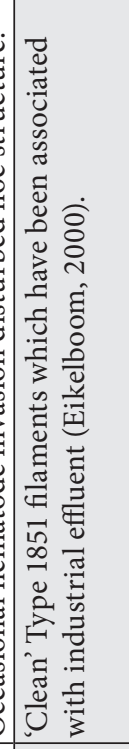 & 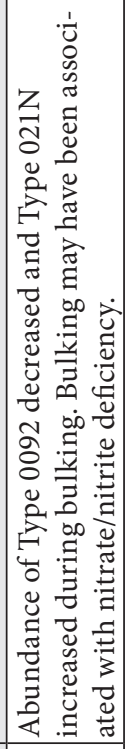 & 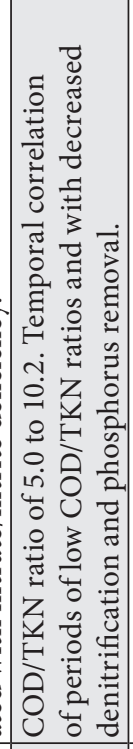 & 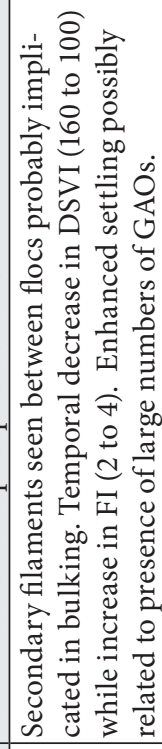 & 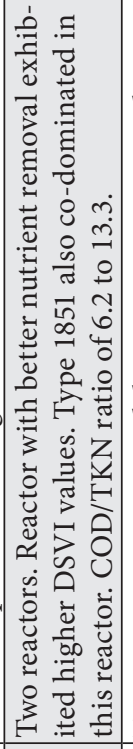 & 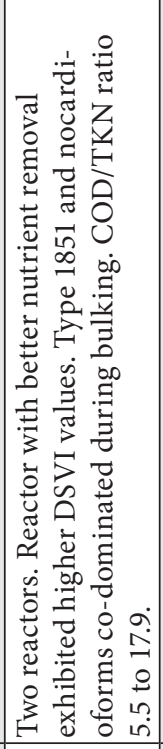 & 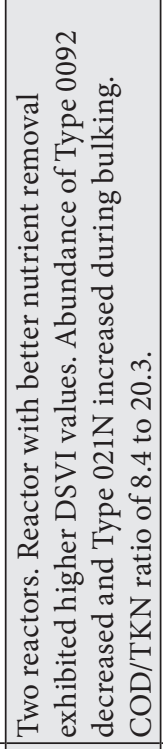 & & 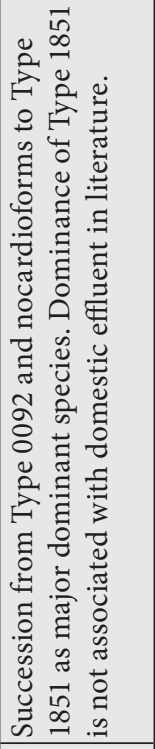 & 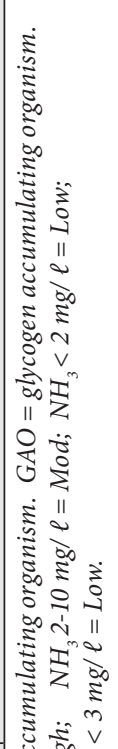 \\
\hline 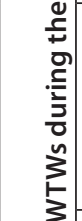 & 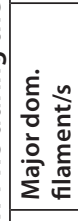 & 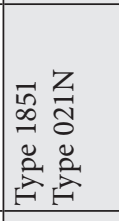 & 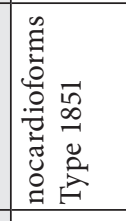 & 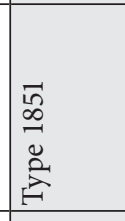 & 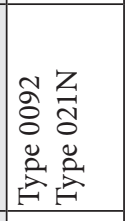 & 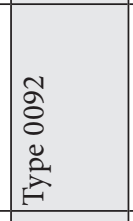 & 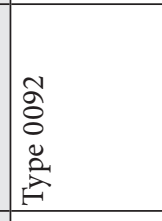 & 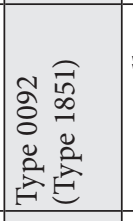 & 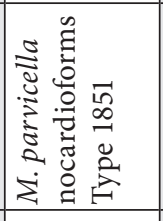 & 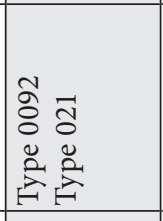 & 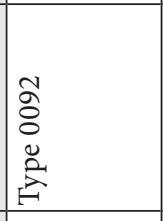 & 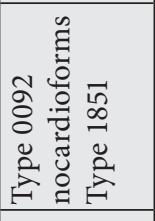 & \\
\hline 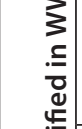 & 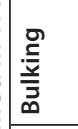 & $\stackrel{\infty}{\approx}$ & $\stackrel{\circlearrowright}{\approx}$ & $\ddot{z}$ & 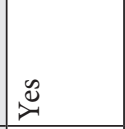 & $\not{z}$ & $\overbrace{i}^{\infty}$ & $z_{z}$ & 竧 & 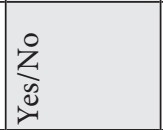 & $\begin{array}{l}\stackrel{0}{z} \\
\grave{o}\end{array}$ & 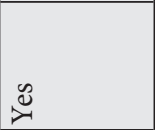 & \\
\hline 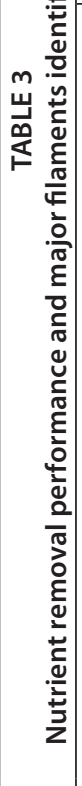 & 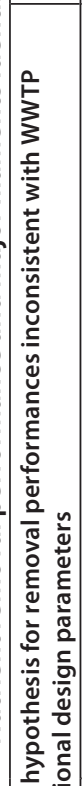 & 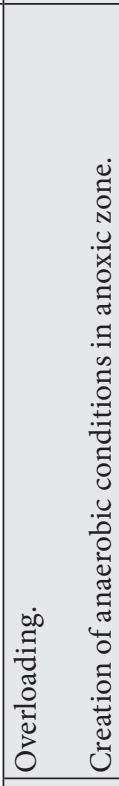 & 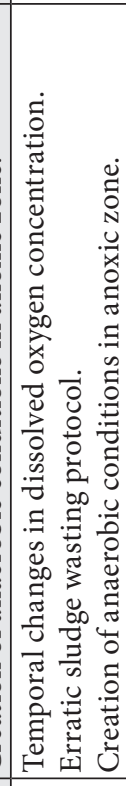 & 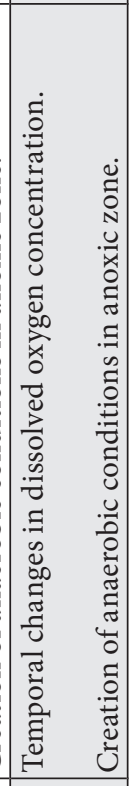 & 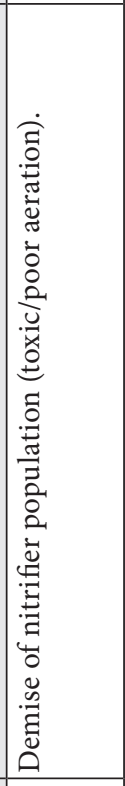 & 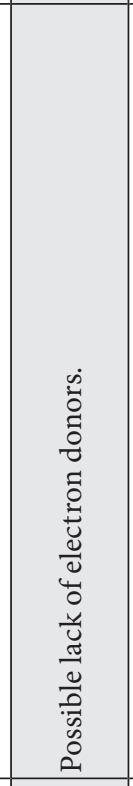 & & 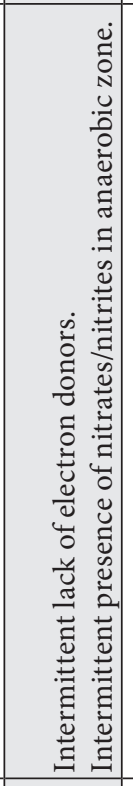 & 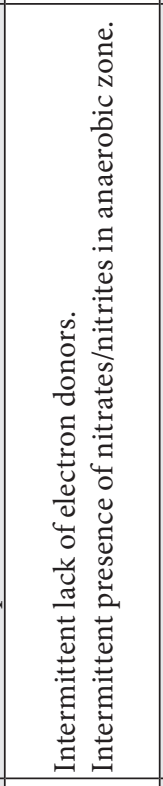 & 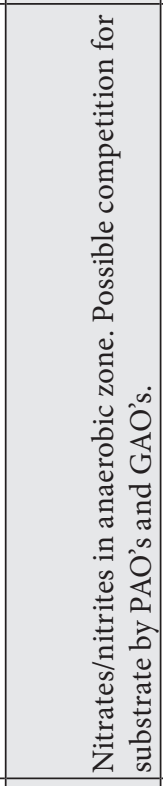 & 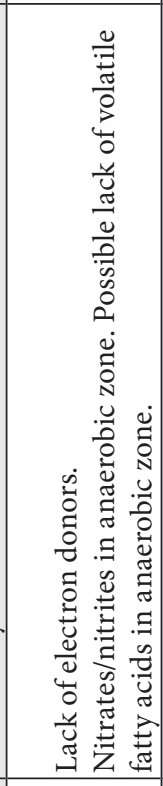 & 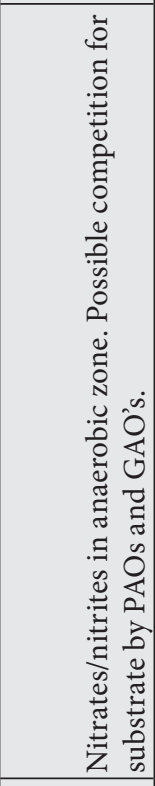 & है \\
\hline & 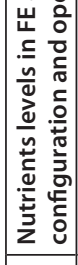 & 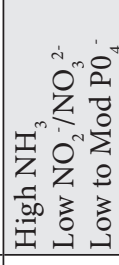 & 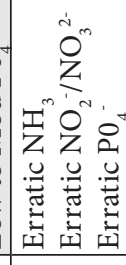 & 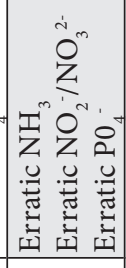 & 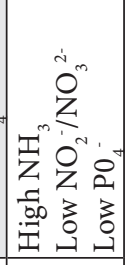 & 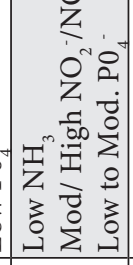 & 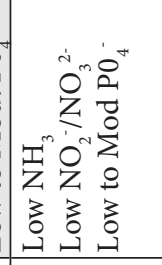 & 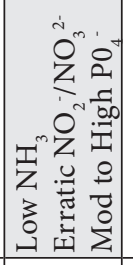 & 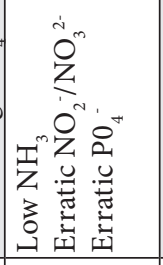 & 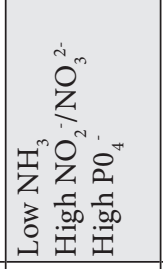 & 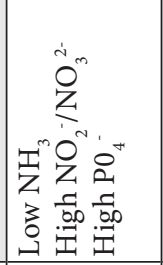 & 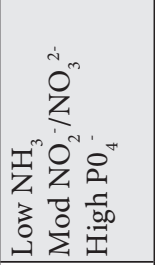 & \\
\hline & 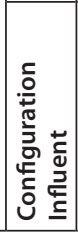 & 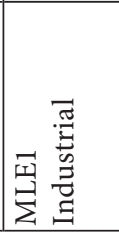 & 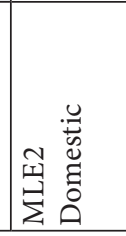 & 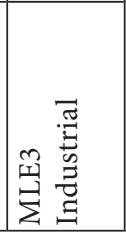 & 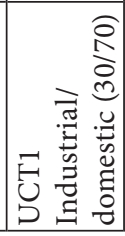 & 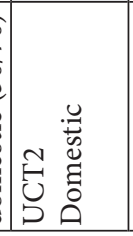 & 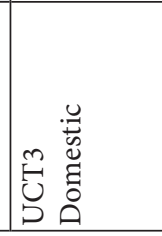 & 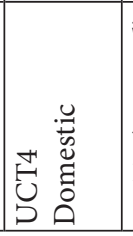 & 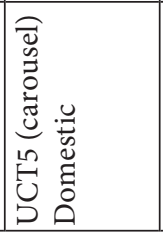 & 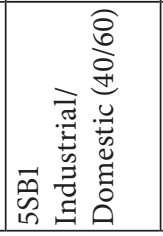 & 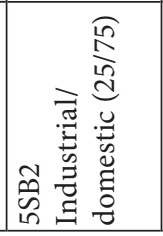 & 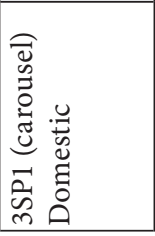 & \\
\hline
\end{tabular}


and $\mathrm{pH}$, as well as the compilation of VFA profiles in the anaerobic zones of full-scale systems is needed to validate these hypotheses.

\section{CONCLUSIONS AND RECOMMENDATIONS}

Filament identification and microscopic floc characterisation can assist WWTW operators to diagnose and correct performance problems in a proactive rather than reactive manner. In this study, definite trends were noted in the selection of particular filamentous morphotypes related to WWTW configuration and/or operational parameters. In particular, the selection of Eikelboom Type 0092 was observed in all of the BNR WWTWs. This was contrary to the results from a similar survey conducted in Durban, demonstrating that results cannot be extrapolated from one geographical location to another. No comprehensive, long-term nationwide filamentous survey has been performed in South Africa. In order to gain insight into the effect of local geography, WWTW configuration and operational parameters on the selection of filamentous morphotypes, such a study is recommended. The experimental design should include filament identification by traditional microscopy and a molecular method (e.g. FISH). The use of more than one technique should limit the effect of technical bias and ensure that any geographical differences that are noted in the filamentous populations are genuine.

\section{ACKNOWLEDGEMENTS}

The authors would like to thank staff from the City of Cape Town, particularly Ingrid Thomson and Dr Heidi Richards from Scientific Services, for their assistance.

\section{REFERENCES}

ARUGA S, KAMAGATA Y, KOHNO T, HANADA S, NAKAMURA K and KANAGAWA T (2002) Characterization of filamentous Eikelboom type $021 \mathrm{~N}$ bacteria and description of Thiothrix disciformis sp. nov. and Thiothrix flexilis sp. nov. Int. J. Syst. Evol. Microbiol. 52 1309-1316.

BEER M, SEVIOUR EM, KONG Y, CUNNINGHAM M, BLACKALL LL, and SEVIOUR RJ (2002) Phylogeny of the filamentous bacterium Eikelboom Type 1851, and design and application of a 16S rRNA targeted oligonucleotide probe for its fluorescence in situ identification in activated sludge. FEMS Microbiol. Lett. 207 $179-183$.

BLACKBEARD JR, GABB DMD, EKAMA GA and MARAIS GRV (1986) Identification of filamentous organisms in nutrient removal activated sludge plants in South Africa. Water SA 14 29-33.

CASEY TG, WENTZEL MC and EKAMA GA (1999a) Filamentous organism bulking in nutrient removal activated sludge systems Paper 9: Review of biochemistry of heterotrophic respiratory metabolism. Water SA 25 409-4241.

CASEY TG, WENTZEL MC and EKAMA GA (1999b) Filamentous organism bulking in nutrient removal activated sludge systems. Paper 10: Metabolic behaviour of heterotrophic facultative aerobic organisms under aerated and unaerated conditions. Water SA 25 425-442.

CASEY TG, WENTZEL MC and EKAMA GA (1999c) Filamentous organism bulking in nutrient removal activated sludge systems. Paper 11: A biochemical/microbiological model for proliferation of anoxic-aerobic (AA) filamentous organisms. Water SA 25 443-451.

CHERNOUSOVA EY, BELOUSOVA EV, GAVRISH EY, DUBININA GA, TOUROVA TP and GRABOVICH MY (2012) Molecular phylogeny and taxonomy of colorless, filamentous sulfur bacteria of the genus Thiothrix. Microbiol. 81 332-341.

CLESCERI S, GREENBERG AE and EATON AD (2005) Standard Methods for the Examination of Water and Wastewater. APHA,
AWWA and WEF, Washington DC.

EIKELBOOM DH (2000) Process Control of Activated Sludge Plants by Microscopic Investigation. IWA Publishing, London.

EKAMA GA, MARAIS GVR, SIEBRITZ IP, PITMAN AR, KEAY GFP, GERBER A and SMOLLEN M (1984) Theory, Design and Operation of Nutrient Removal Activated Sludge Processes. WRC Report No. TT 16/84. Water Research Commission, Pretoria.

ESCHENHAGEN M, SCHUPPLIER M and ROSKE I (2003) Molecular characterization of the microbial community structure in two activated sludge systems for the advanced treatment of domestic effluents. Water Res. 37 3224-3232.

GUO F and ZHANG T (2012) Profiling bulking and foaming bacterial in activated sludge by high throughput sequencing. Water Res. 46 2772-2782.

GULEZ G and DE LOS REYES III FL (2009) Multiple approaches to assess filamentous bacterial growth in activated sludge under different carbon sources. J. Appl. Microbiol. 106 682-691

JENKINS D, RICHARD MG, DAIGGER GT (2004) Manual on the Causes and Control of Activated Sludge Bulking, Foaming and Other Solids Separation Problems. CRC Press, Boca Raton. IWA Publishing, London.

KANAGAWA T, KAMAGATE Y, ARUGA S, KOHNO T, HORN M and WAGNER M (2000) Phylogenetic analysis of and oligonucleotide probe development for Eikelboom Type $021 \mathrm{~N}$ filamentous bacteria isolated from bulking activated sludge. Appl. Environ. Microbiol. $665043-5053$.

KUJAWA K and KLAPWIJK A (1996) The effect of the sludge loading rate and the nature of carbon source on denitrification potential. Research note. Wageningen Agricultural University, Wageningen.

LACKO N, BUX F and KASAN HC (1999) Survey of filamentous bacteria in activated sludge plants in KwaZulu-Natal. Water SA 25 63-68.

LAKAY MT, KETLEY D, WARBURTON C, DE VILLIERS M, CASEY TG, WENTZEL MC and EKAMA GA (1999) Filamentous organism bulking in nutrient removal activated sludge systems: Paper 7 - Exploratory experimental investigations. Water SA 25 283-396.

LIU WT, NAKAMURA K, MATSUO T and MINO T (1997) Internal energy-based competitions between polyphosphate and glycogen accumulation bacteria in biological phosphorus removal reactions: effect of P/C feeding ratio. Water Res. 31 1430-1438.

LIU RL and SEVIOUR RJ (2001) Design and application of oligonucleotide probes for fluorescent in situ identification of the filamentous bacterial monotype Nostocoida limicola in activated sludge. Environ. Microbiol. 3 551-560.

MADONI P, DAVIOLI D and GIBIN G (2000) Survey of filamentous microorganisms from bulking and foaming activated sludge plants in Italy. Water Res. 34 1767-1772.

MADONI P and DAVIOLI D (2002) Control of Microthrix parvicella in activated sludge. FEMS Microbiol. Ecol. 12 277-284.

MARRENGANE Z, KUMAR SKS, PILLAY L and BUX F (2011) Rapid quantification and analysis of genetic diversity among Gordonia populations in foaming activated sludge plants. J. Basic Microbiol. 51 415-423.

MARTINS AMP, PAGILLA K, HEIJNEN JJ and VAN LOOSDRECHT MCM (2004) Filamentous bulking sludge - a critical review. Water Res. 38 793-817.

NIELSEN PH, ROSLEV P, DUEHOLM TE and NIELSEN JL (2002) Microthrix parvicella, a specialized lipid consumer in amaerobicaerobic activated sludge plants. Water Sci. Technol. 46 73-80.

NIELSEN PH, KRAGELAUND C, SEVIOUR RJ and NIELSEN JL (2009) Identity and ecophysiology of filamentous bacteria in activated sludge. FEMS Microbiol. Rev. 33 969-998.

NOUTSOPOULOS C, MAMAIS D and ANDREADAKIS A (2006) Effect of solids retention time on Microthrix parvicella growth. Water SA 32 315-321.

OEHMAN A, LEMA, PC, CARVALHO G, YUAN Z, KELLER J, BLACKALL LL and REIS MAM (2007) Advances in enhanced biological phosphorus removal: from micro to macro scale. Water Res. 41 2271-2300.

RAMOTHOKANG TR, DRYSDALE GD and BUX F (2003) Isolation and cultivation of filamentous bacteria implicated in activated sludge bulking. Water SA 29 405-410. 
RICHARD MG, JENKINS D, HAO O and SHIMZU G (1982) The isolation and characterization of filamentous micro-organisms from activated sludge bulking. Report 81-82. Sanitary Engineering and Environmental Health Research Laboratory, University of California, Berkeley.

ROELS T, DAUWE F, VAN DAMME S, DE WILDE K and ROELANDT T (2002) The influence of PAX-14 on activated sludge systems and in particular on Microthrix parvicella. Water Sci. Technol. 46 487-490.

ROSSETTI S, TOMEI ML, NIELSEN M and TANDOI V (2005) Microthrix parvicella, a filamentous bacterium causing bulking and foaming in activated sludge: a review of current knowledge. FEMS Microbiol. Res. 29 49-64.

SPIERS LBM, MCILLROY SJ, PETROVSKI S and SEVIOUR RJ (2009) The activated sludge bulking filament Eikelboom morphotype 0914 is a member of the Chloroflexi. Environ. Microbiol. Rep. 3 159-165.
TSAI M-W, WENTZEL MC and EKAMA GA (2003) The effect of residual ammonia concentration under aerobic conditions on the growth of Microthrix parvicalla in biological nutrient removal plants. Water Res. 37 3009-3015.

STROM PF and JENKINS D (1984) Identification and significance of filamentous microorganisms in activated sludge. J. Water Pollut. Control 56 449-459.

WAGNER M, AMANN R, KAEMPEER P, ASSMUS B, HARTMANN A, HUTZLER P, SPRINGER N and SCHLEIFER K-H (1994). Identification and in situ detection of Gram negative filamentous bacteria in activated sludge. Syst. Appl. Microbiol. 17 405-417. YOON D-N, PARK S-J, KIM S-J, JEON CO, CHAE J-C and RHEE S-K (2010) Isolation, characterization and abundance of filamentous members of Caldilineae in activated sludge. J. Microbiol. 48 275-283. 
http://dx.doi.org/10.4314/wsa.v40i4.10 Available on website http://www.wrc.org.za

ISSN 0378-4738 (Print) = Water SA Vol. 40 No. 4 October 2014 ISSN 1816-7950 (On-line) = Water SA Vol. 40 No. 4 October 2014 